INTERNATION AL JOURNAL OF RESEARCHES IN BIOSCIENCES, AGRICULTURE AND TECHNOLOGY

(C) VISHWASHANTI MULTIPURPOSE SOCIETY (Global Peace Multipurpose Society) R. No. MH-659/13(N) WWw.vmsindia.org

\title{
AN ANDROID APPLICATION FOR AMPLIFING CHILDERN SECURITY
}

\author{
S. Umratkar and R. Kumar \\ Department of Computer Engineering \\ Jagadambha College of Engineering \& Technology, Yavatmal (M.S.) India \\ umratkar.sneha187@gmail.com
}

\begin{abstract}
:
This paper focuses on the android mobile application which is mainly developed for children security. This application helps in tracking the school van to and from school and send the notification to the pare nt for the status of children. The database of parent, driver and student is created in this application where student and driver database is created in the school side and parent database is created in parent side so that it can be efficiently used by both the side. For tracking the school van GPS and other two methods are used oll tower triangulation and IP address tracking, using these methods van can be tracked more efficiently. This paper explains use of Broadcast reœiver and SQLite for Sending the notification, getting the location of van and for storing the data and performing various operations such as Save, Dele te, Modify and Update.

Keyw ords-Android, securit, GPS, Broadcast Receiver, SQLite, Cel Tower Triangulationl
\end{abstract}

\section{Introduction:}

\section{Increasing android trends}

With the explosive increase in mobile apps the things such as checking an email, surfing web, tracking location becomes so easy. Various searches show that the more and more pc client software are now migrating to the mobile devices. General statistic gives the amount of total download in 2012 was 45 billion which is double than number of downloads in 2011 and in 2013 it became 81 billion and in 2014 it will again double or more. Maximum apps downloaded were from android. As statistics shows more than $85 \%$ of the market is covered by android. Android phones are available with everyone as they come with various price ranges so everyone carries Smartphone. The issues like children safety embedded in smart phone can be very helpful and can reach to the maximum segment of the society. This mobile phone application is developed considering the student going to the pre-primary i.e. toddler group. These children are so young that they can't talk and understand the things so parents are highly worried in such case that is the reason why to track them is very important. Now a day's cameras are installed in all the school campus so the things happening in the school campus are always under observation but when children are travelling to the school or from the school the parents won't have any way to track them so this application will do that work [1].

\section{Motivation}

Various applications are developed in android for tracking the family members and friends but till now no application is developed in android for security of the children while travelling to and from the school. Before 8 to 9 month the shameful incidence had happen to the one of the reputed school in Bangalore, school authority and parent where helpless because they didn't have any option to track the Bus and the Van driver, who were suspected to be the culprits in the case, so it's a need to have an application which can track the School van and parent should get the notification about the van status at any instance of time so that such incidences can be avoided.

\section{Our work}

In this paper we are explaining application named SecureChild: Children Tracking Android Application, this application can be used in parent as well as school side. Following are the functionalities provided by SecureChild

1. The tracking of school van can be done and parent will get the notification periodically about the status of the van.

2. The status of child will be given to the parent such as reached, left and absent.

3. Parent can inform the school about the absentee of the child.

4. The driver and babysitters details are given to the parent

5. Every time when babysitter and driver change the notification will be given to the parent.

6. Driver and parent can start and stop the tracking service as per requirement.

\section{RELETED WORK}

Chandra A, Jain S, Qadeer M A [2], has proposed the location sharing system based on Global Positioning System and General Packet Radio Services (GPRS) using J2ME, PHP, and MYSQL which gives the user current location, send this location using SMS and view them on Google map. But it has implementation problem and accuracy problem, and has no centralizes database as well as some security issues and have no two way communication between Web 
server and device Saranya, J, Selvakumar J. [4] focuses on implementing children tracking system for every child attending school it includes a child module and two receiver modules for getting the information about the missed child on periodical basis. The child module includes ARM7 microcontroller (1pc 2378) Global positioning system (GPS) Global system for mobile communication Global System for Mobiles (GSM) Voice playback circuit and the receiver module includes Android mobile device in parent's hand and the other as monitoring database in control room of the school but this method needs lot of setup and preparation which is not suitable.

Ito, A.,Ohta, T.,Inoue, S. [5],[10] has given, new security system for children on school route by using mobile ad hoc network that is constructed based on mobile phone with Bluetooth function. About 700 students used this system for four months. And it is found that this system has good performance and accuracy to keep safety of students on the way to school. As now a day's Bluetooth is rarely used. And more advance functionalities are available.

Daisuke Igaue, Takumi Ichimura [9] has developed an android application for kid's protection which consists of 2 layered learning where Profit-Sharing works to plan a target position in higher layer and Q-learning trains the state-action pair to the target in lower layer. They have developed Android application which the agent can notify that danger situation close to the child by the acquired knowledge from the previous learning result.

\section{Designing User Interface}

It describes designing of user interface for SecureChild. User Interface is developed in XML and JAVA, static components are developed using XML and dynamic component is in JAVA. There are various component of User Interface (UI) these are called as selection widgets. The widget package contains (mostly visual) User Interface elements to use on Application screen. Android application can be designed using set of selection widgets as per the requirements. Linear Layout, Relative Layout, ScrollView, GridView, TextView, ListView, Button, ImageView, Spinner, EditText and AutoComplete Textview etc are some of the widgets used in SecureChild application. Every selection widget has some properties which will give them physical appearance and programmatically identity.

\section{Linear Layout}

Linear Layout is a view group that aligns all children in a single direction, vertically or horizontally. This is the default layout given. The layout direction can be specified by setting orientation. All children of a Linear Layout are stacked one after the other so a vertical list will only have one child per row, no matter how wide they are, and a horizon tal list will only be one row high (the height of the tallest child, plus padding). A Linear Layout respects margins between children and gravity.

Ex: If there are three Text field's and two of them declare a weight of 1 , while the other is given no weight, the third text field without weight will not grow and will only occupy the area required by its content. The other two will expand equally to fill the space remaining after all three fields are measured. If the third field is then given a weight of 2 (instead of 0 ), then it is now declared more important than both the others, so it gets half the total remaining space, while the first two share the rest equally.

\section{Relative Layout}

Relative layout group displays child views in relative positions. The position of each view can be specified as relative to sibling elements (such as to the left-of or below another view) or in positions relative to the parent Relative Layout area (such as aligned to the bottom, left or center). A Relative Layout is a very powerful utility for designing a User Interface because it can eliminate nested view groups and keep layout hierarchy flat, which improves performance. If application need using several nested Linear Layout groups, it can be replace with a single relative layout. Relative Layout lets child views specify their position relative to the parent view or to each other (specified by ID). So can be aligned two elements by right border, or make one below another, cantered in the screen, centered left, and so on. As in Figure 1 general structure of relative layout and one used in SecureChild is shown. By default, all child views are drawn at the topleft of the layout, so it is mandatory to define the position of each view using various layout properties available RelativeLayout.LayoutParams. It has many properties like layout_below, layout_alignParentTop, layout_centerVertical, layout_toRightOf etc.

\section{Toast}

Toast provides simple feedback about an operation in a small popup. It only fills the amount of space required for the message and the current activity remains visible and interactive. For example, navigating away from an email before you send it triggers a "Draft saved" toast to let you know that you can 
continue editing later. Toasts automatically disappear after some time which can also be set in the code. A standard toast notification appears near the bottom of the screen, centered horizontally. But this position can be change with the setGravity(int, int, int) method. This accepts three parameter gravity constant, $\mathrm{x}$ position and y-position offset we can make toast appear in top left corner by setting.

Toast.setGravity(Gravity.TOP|Gravity.LEFT， 0, $0)$;

\section{ListView}

List View is a view group that displays a list of scrollable items. The list items are automatically inserted to the list using an Adapter that pulls content from a source such as an array or database query and converts each item result into a view that's placed into the list. It is possible to customize the ListView means we can add many item in each cell and that cell can be replicated according to the total items in the list. Figure 1 shows the ListView in SecureChild which has one edit Text and three Buttons.

\section{Spinner}

It is a view that displays one child at a time and lets the user pick among them. The items in the spinner come from the adaptor associated with this view. It also has all properties like height, width, id, gravity etc. Figure 1 shows the spinner Batch which shows two batches Morning and Afternoon and we can select any one of them at a time.

\section{EditText}

Edit text is a thin veneer over TextView that configure itself to Editable.

It can be mainly used in entering the values at the run time such as user name and password.

Hint is given which can be set in the code so that user will understand about the field; hint will be visible when no action is performed on the EditText.

\section{TextView}

Displays text to the user and optionally allows them to edit it. A TextView is a complete text editor; however the basic class is configured to not allow editing. To allow users to copy some or all of the TextView's value and paste it somewhere else, set the XML attribute android:textIsSelectable to "true" or call setTextIs Selectable(true).

The textIsSelectable flag allows users to make selection gestures in the TextView, which in turn triggers the system's built-in copy/paste controls. In the above Figure 1 Enter the School details is the TextView.

\section{Button:}

Button is used to set the onClick listener so that some action can be performed on click of button it also have all the properties that TextView has. In the above Figure $1 \mathrm{R}, \mathrm{L}, \mathrm{A}$ are three buttons.

\section{GPS AND BROADCAST RECEIVER}

The Global Positioning System (GPS) consists of 27 Earth-orbiting satellites (24 in operation and three extras in case one fails). Developed by the USA as a military navigation system, but soon it opened to other civilian uses. Each of these 3,000- to 4,000-pound solar-powered satellites circle the globe at about 12,000 miles $(19,300 \mathrm{~km})$, making two complete rotations every day that means it rotate the speed double the speed of earth.

The orbits are arranged so that at anytime, anywhere on Earth, there are at least four satellites "visible" in the sky. A GPS receiver's job is to locate three or more of these satellites, figure out the distance to each, and use this information to deduce its own location. This operation is based on a mathematical principle called trilateration.

There are two types of trilateration 2-D Trilateration and 3-D Trilateration Imagine you are somewhere in the United States and you are TOTALLY lost --for whatever reason, you have absolutely no clue where you are. You find a friendly local and ask, "Where am I?" He says, "You are 625 miles from Boise, Idaho.

You ask somebody else where you are, and she says, "You are 690 miles from Minneapolis, Minnesota." Now you have two circles that intersect. You now know that you must be at one of these two intersection points. If a third person tells you that you are 615 miles from Tucson, Arizona, you can eliminate one of the possibilities. You now know exactly where you are--Denver, Colorado as shown in figure 2 This same concept works in three-dimensional space, as well, but you're dealing with spheres instead of circles this is mainly used for getting the location when object to be tracked is above the surface of earth example if you are travelling through airplane this method is used to track location it is called as 3D trilateration.

\section{Cell Tower Triangulation:}

An alternative method to determine the location is by using the cell towers of a cell phone the distance to three nearby cell towers is used to get the location. Distance of the phone to each antenna could be estimated based upon the lag time between the moment the tower sends a ping to the phone and receives the answering ping back. It is similar to the 2D- 
Trilateration Method. Android Location Provider Chip: The Android API provides Location data based on a variety of methods including: Cell Tower Triangulation, and most commonly GPS chip readings.

GPS is the most common location provider on the Android based phones. It offers the most accuracy. Figure 3 shows an Epson Infineon GPS $(2.8 \times 2.9 \mathrm{~mm})$ the Infineon chip which is used to communicate with the satellite and get the location. Now almost every phone has this chip so it is easy to track the device.

\section{DATABASE AND EXPERIMENTATION}

This includes idea about how to create database of Student, Driver and Parent to get the login id password and how to send the data to the appropriate set of parents, which is initial requirement of this application. Also gives how to edit, delete and save the database.

Here SQLite is used to create database. It is same as SQL the only difference is its light version of SQL means it takes low space and best suitable for mobile phones. SQLite studio is used for checking the tables because it is not possible in phone's sd card to see the tables and values as mobiles we use are formatted so it will not allow to see the database for any application as it is thread to privacy of application.

Login Database: For this application to use, one should have unique login id and password which user has to set at the time of registration.

Once register you can enter login id and password and sign in.

If by mistake you forgot your password by clicking on forgot password button you can get the password as SMS on the mobile number you have entered at the time of registration. For security you have to enter the user id entered while registration.

Here the database is created while registration the table PARENTREG_DATA is created it has 7 columns named EmailId, Password, PhoneNo, Address, Childname, Timings and VanNo user has to enter the values which will be saved in table. The Primary key is automatically added in the table to give each row unique identity. The below figure 5 shows the table PARENTREG_DATA. This table is created in the mobiles SD card but mobile we use does not allow to see it as it will open all the databases of application which is not desirable so in our mobile there is no way to access the tables so I am using Sqlite Studio tool to see the database structure.

For developers all the unformatted mobiles are given which will help them to see the structure of database. It is possible to convert the formatted device to unformatted but it will harm the device so always avoided.

While registration we are creating table which has fields like Email id, password, conform password, phone number, class of learning, section and van no by which your child go to school, among these emailed, password, phone number, child Name, timings and Van number is used to create the table. This database is made for the secure login of user as shown in Figure 5.

Driver Database: Second table is for information at the school side which stores information about Driver details and babysitter details. Driver details includes Driver name, his phone number, address and license number which is very important to track the driver , and babysitter information includes her name and phone number. This information is used when driver or baby sitter changes, the parent which are going through that van whose driver is changed is notified with the details of new driver entered in the table. The database of driver is shown in Figure 6.

Student Database: Third table stores information about the children data this is also at the school side. It contains information about the students like Student name, parent phone number, address, and the very important van no by which child is going to school. This database is used when the status information is sent to the parent stating the current status of the child like left school, reached school and the absent in the school. The table is shown in below figure.

\section{IMPLEMENTATION AND ANALYSIS}

All the activities and its functioning is describe here, Below is the first activity of this application it has two EditText for User Id, Password and four buttons. This application is used by both school and parent so both can login to this application.

When parent use this application for very first time he has to register himself by clicking on register as parent button then second activity will open which will ask the parent various fields like User Id (which mainly should be Email Id), Password, Confirm Password, Mobile Number, Address, Child Name, Class, Section and Van No as shown in figure 9 and 10, this data will be saved in parent data base which is created using SQLite to save all the parent details. As we could see a button named Register at the end of this activity which after click will send the SMS to the school number stating that this particular parent has 
register in this application so please add this number for service.

Ones Parent is registered next time he can Sign In to this application with the same Email Id and Password he has entered at the time of registration. For school side use one unique Login Id and Password is given and it will be given to those who will use this application from school side. This login Id and password is hard coded so that no one can change it. The next button is for defining terms and policies of this application, which include that this application may charge you an SMS charge when you first time register this Activity as shown in figure 11 .

If parent forgot the password he can get it again by entering the email id by click on "click here if forgot password" text and you will get the SMS stating your password from the database. And last button is for the login with Facebook credential. This is for adding more security to the application and adds value to it. As this application is not yet published in play store so it is not available to all so developer will decide who are all can use this application. Once you click on the Login with Facebook button you will get the following screen shown Figure 11 and 12 .

By entering Login Id and Password of your Facebook account you can login to this application. If the login credentials are correct then application will revert with the message that you are authorized user click ok and the parent side activity will open.

When we use school side of this application with provided login Id and Password we will have the screen which will direct to the different activities as shown in Figure 13. Here the Login Id and Password is hardcoded so can't be change. After login SchoolRegActivity will open. It has five buttons Track On, Add Student, Add Driver and Babysitter details, Send Status to parent and the last is Back to main Screen.. Track On will be used by Drier driving the School Van he need to login and open the Track On and start driving so that application will start working it will get the latitude and longitude of every location and accordingly send the SMS to parent regarding the current status of Van.

As I have already mention the database of student which are using Van facility should be present in the school side on clicking the button Add Student all the necessary student information is added with the van no and batch i.e. Morning batch and afternoon as shown in above Figure 14. It has three buttons Save, Edit and Exit. After entering all the student details on clicking button Save the data of student will be inserted into student database and saved if in case we want to edit the that data on clicking edit we can either edit by entering just the phone number all the corresponding fields get selected and deleted from the database and new data can be entered and saved into the database.

The next button is Add Driver and Babysitter details here as this application is targeted the student who are mainly going to pre-primary they always have babysitter sitting in van with them to make them sit in the van properly, and help them to get down from the van so all the information about the driver and baby sitter should be given to parent so that parent will be aware of any changes in them. The driver details activity is shown in figure 15

The next window is send status to parent that the child is reached school left school and absent in the school as shown in Figure 16 here we have used the list view which takes the values from database according runtime selection of Van No and Batch as shown below. It may happen that if the school van is stolen so that come with the fake driver and babysitter to pick up the children at the regular time. Parent will think that the driver and baby sitter might be new so parent will send their kids as normal but it is very dangerous so to avoid this situation all the information regarding the driver and baby sitter will be given in the form of SMS and when the driver details are edited then also an SMS will automatically go to the parent who are going through that Van.

The figure 16 shows two layout the upper one is relaytive layout which has two text view, two spinner and one button the text view gives the information about the activity and direct the user the two spinner is used for van no and batch selection in this we have added 6 van so user has to select one of them and it the both values selected user will click ok once ok button is clicked the button get disappear so that only student with that perticular selected values will appear on the screen. The other layout used is ScrollView because the number of student coming by van cant be mapped in relaytive or linear layout so ScrollView is used. This layout reflects the ListView whose one cell contains the EditText and the three buttons EditText shows the name of student and three buttons gives the status such as reached school left school and absent school by Green:R, Blue:L and Red:A colour : Named buttons. 
When the van enters into the school premises the Teacher available in the campus will stand at the gate to take the student inside from the van who will be using this application. Teacher will select the Van No and Batch and the student coming from that Van will be opend now teacher will click the button R:Green if the Advait, Dhruv and Gargee enters in the school andclick the button A: Red if Arishka didn't come so the parents of Advait, Dhruv and Garee will get the SMS that their children reached the school and Arishkas parent will get the message thet Your child didn't come today.

The Last Button is to go back to main screen.

\section{Advantages}

It gives Smart application based on android platform for tracking the School going children while commuting to and from the school which ensures safety in transition. It establishes real time Global Positioning System tracking of School Vehicle in android apps. (Application) It gives database containing each Student Name; Parents Contact Number, Email Id, Class / Section, School timings and address etc. Driver and Babysitter details will be also provided to the parent to protect from situations such as stolen school bus. Integrating this app with Facebook avails the access through it and increases its security. Without Internet connection also the status of child and the changes in the Driver and Babysitter can be sent to parent. Licenses Number given to parent will help them to track the driver.

\section{Limitations:}

This application has main drawback that is; Internet connection is required for tracking the current location of School Van without internet connection current status of School van cannot be obtained. Manual input is required every time for sending the status of student to the parent so one person always need to take the children into the School and to make them sit into School Van. This app is developed only for android platform but not for other such as iOS (Apples products) (input output system) and windows. An Android phone is required for this application to use.

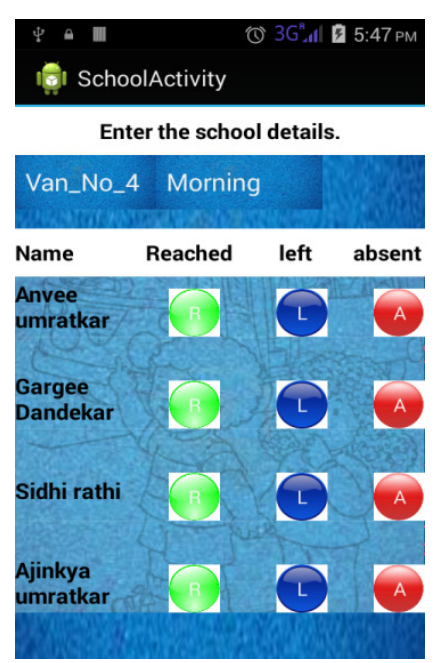

Figure 1: Activity showing Button, Relative Layout, ListView, EditText, TextView and Spinner

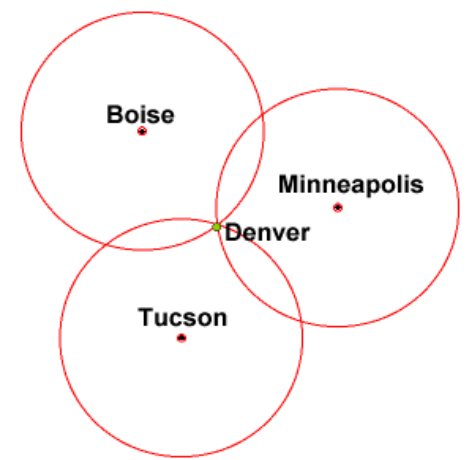

Figure 2: 2D Trilateration

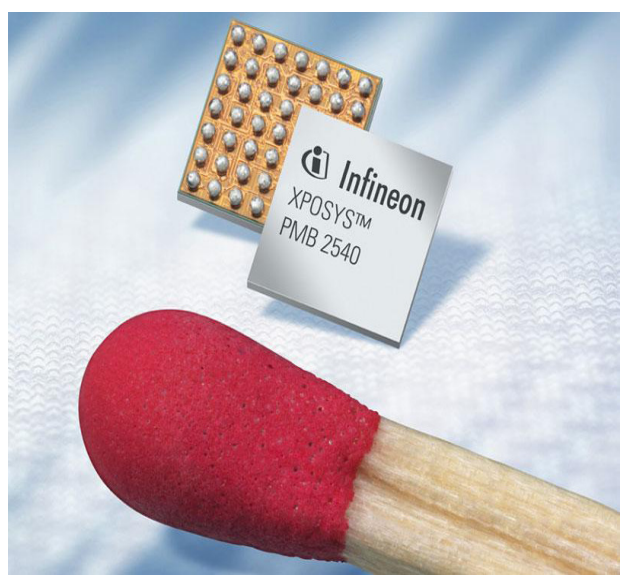

Figure 3: Infineon Chip Working of GPS, Infineon chip and android program is shown in Figure4. 

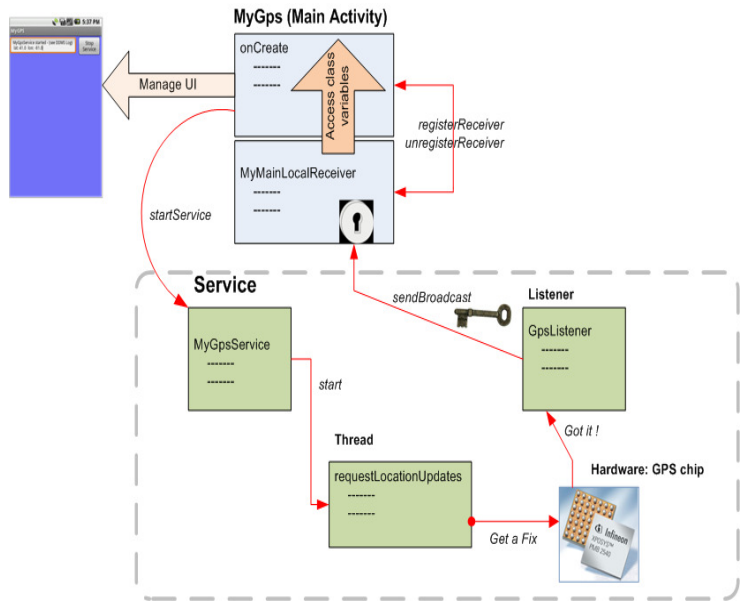

Figure 4: Obtain Location from Global Positioning System

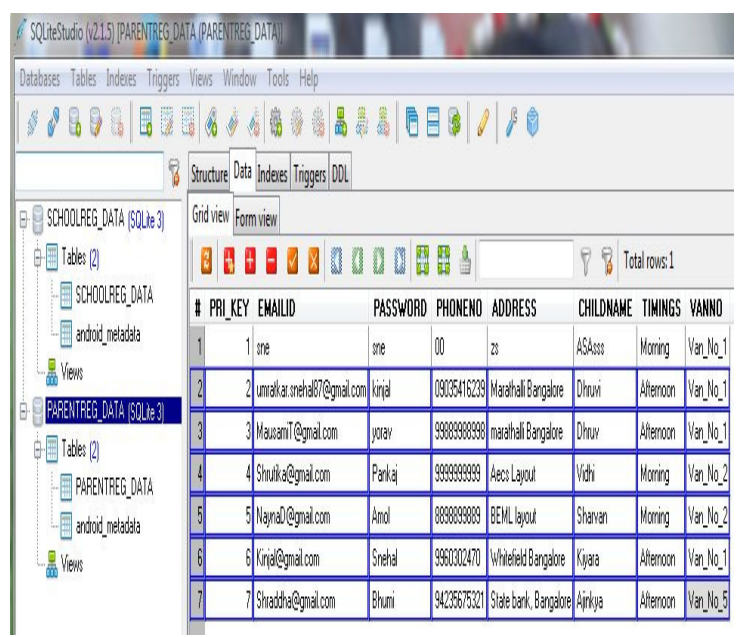

Figure 5: Parentreg_data

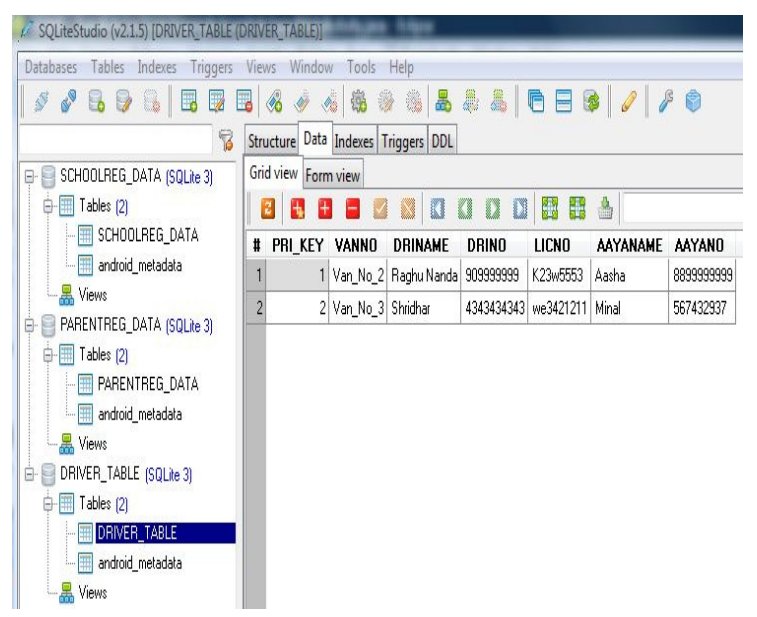

Figure 6: Driver_data

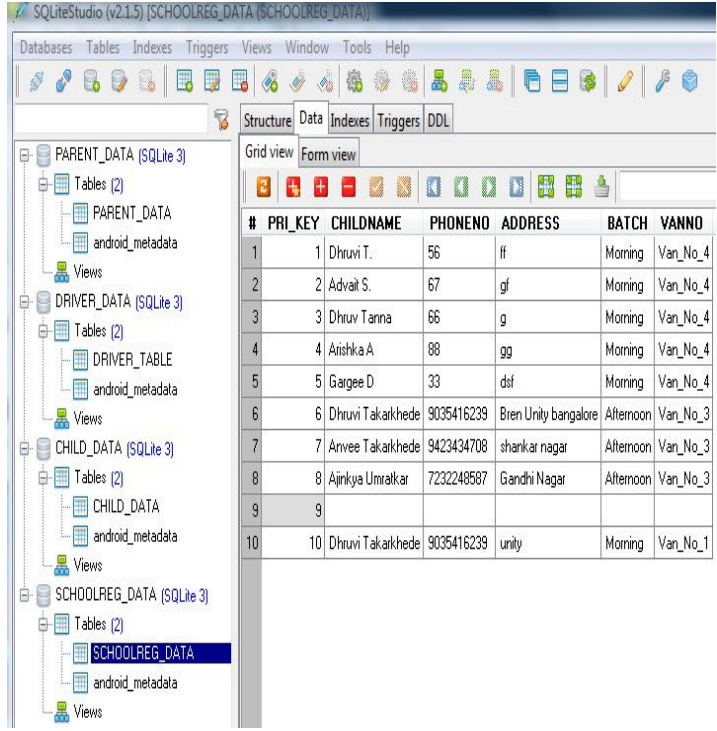

Figure 7: Schoolreg_data

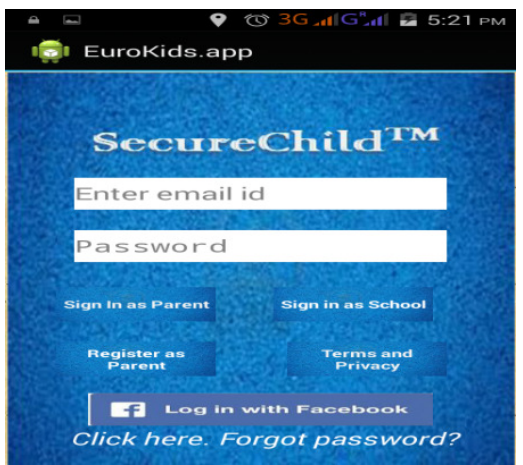

Figure 8: Main Activity

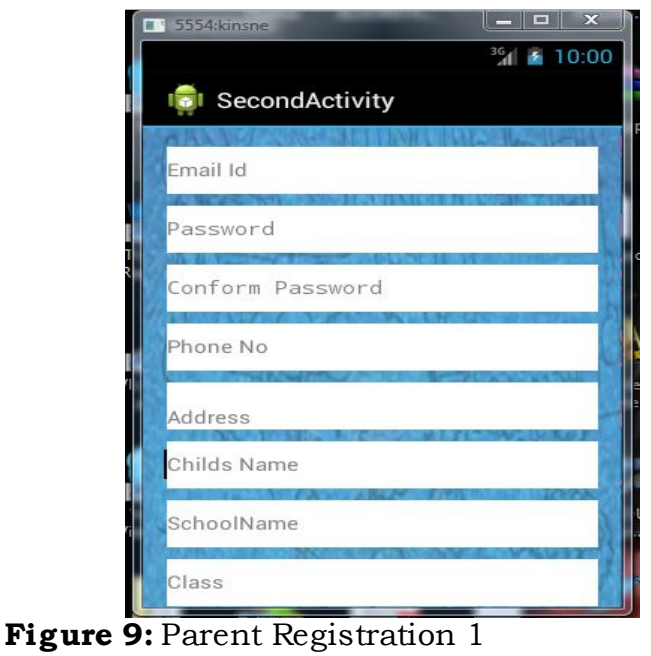

Figure 9: Parent Registration 1 


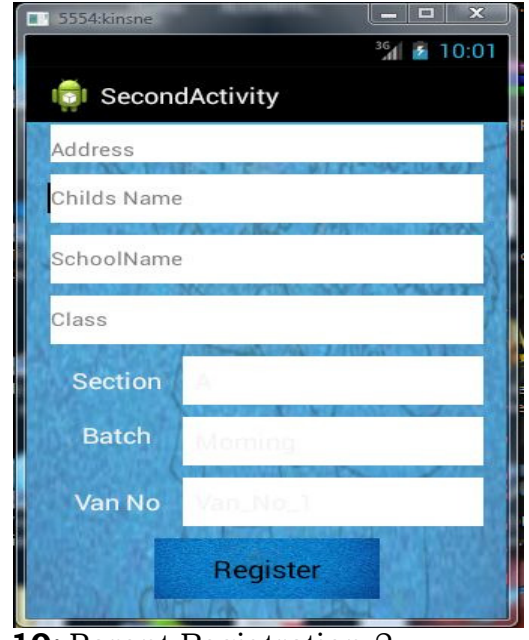

Figure 10: Parent Registration 2

Terms_Privacy_Activity
Terms and Privacy
1. You will be charged SMS charge at
the time of registration.
2. For trcking the Van an internet
connection is required.
3. This application tries to give your
child security but does not garenty $100 \%$
security.
4. This application will track School van
not the single child.
5. This application Track location only
when the application is ON.
Thank You!

Figure 11: Terms and privacy Activity

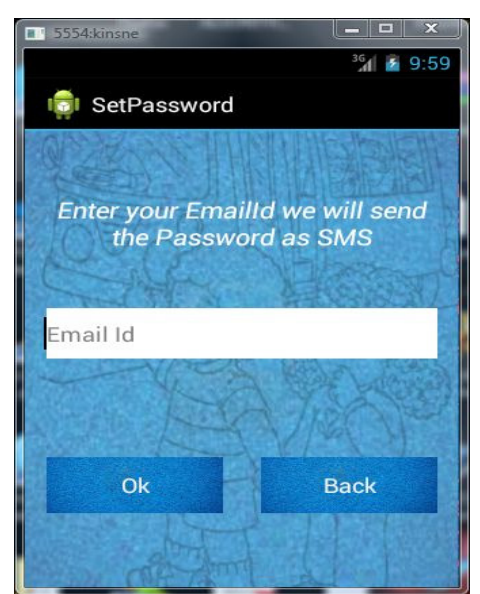

Figure 12: Forgot Password Activity

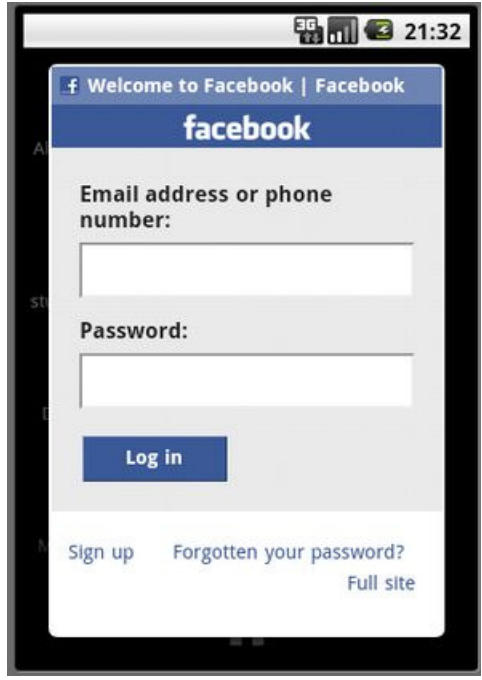

Figure 13: Facebook Login Activity 1

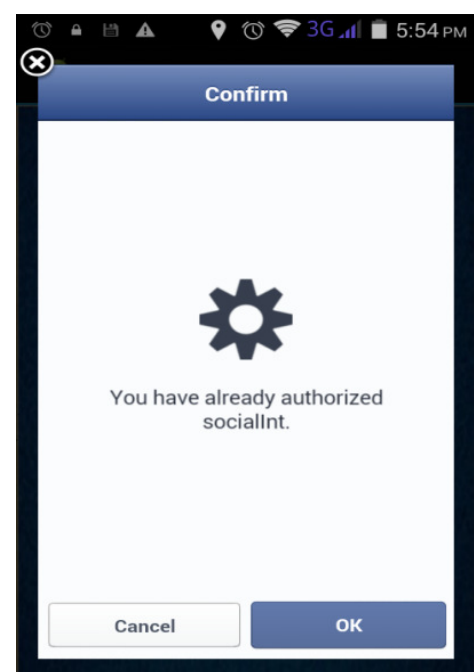

Figure 14: Facebook Login activity 2

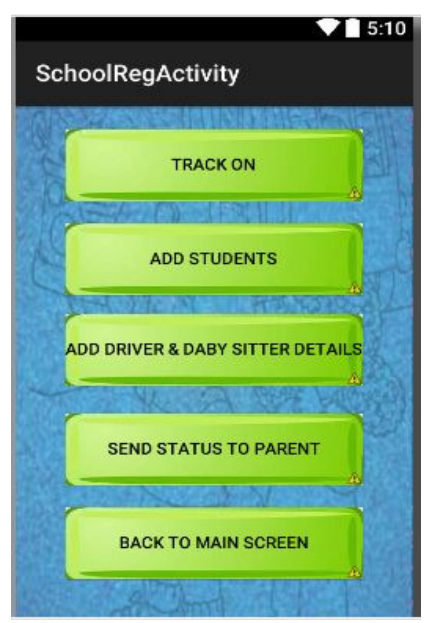

Figure 15: Main Navigating Activity at school side 


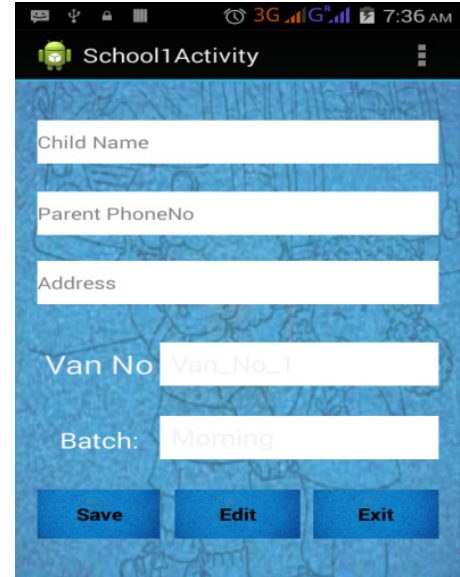

Figure 16: Student Info Activity

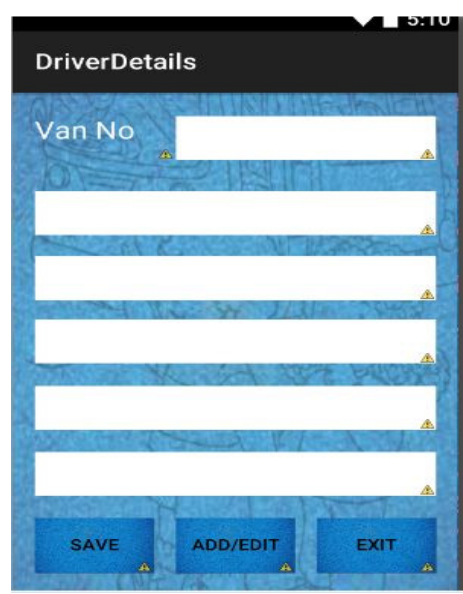

Figure 17: Driver info Activity

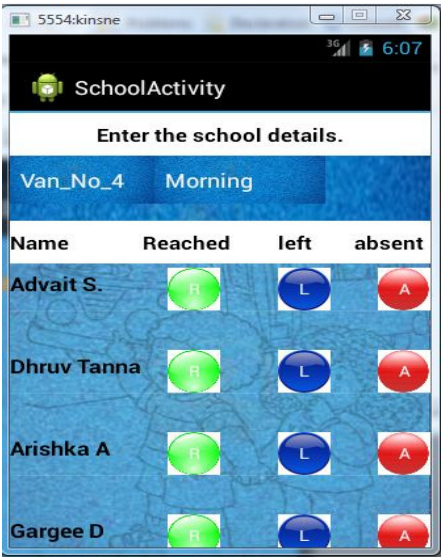

Figure 18: Status Sending Activity

\section{FUTURE WORK}

As this application is developed in Android platform so it will not work for other Operating System devices in future I would like to develop it for iOS as well. Many other options to track the Van can also be added into this application such as Van Speed limits Checker, to limit the speed of Van in School Zone and speed limit Zone. Integrating this application with the School App to enhance its feature can also be done in future. The most important Challenge is to generalize this application so that many schools can use it and different databases should be created for different schools as per their requirements.

The current location of van at any instance of time can't be provided to the parent on demand because it needs the server integration of this project which needs space on server and setting alarm manager to send the van location periodically to the server and then on user demand get the latest location coordinates. So I would like to do it in future on demand from school.

\section{Acknow ledgments:}

I avail this opportunity to express my deep sense of gratitude and whole hearted thanks to my guide Prof. Ram Kumar of Jagadambha College of Engineering \& Technology, Yavatmal for substantial guidance and cooperation. He has provided all the facilities whenever I need and mostly for his gracious encouragement, advice and guidance.

I also express my gratitude to Dr. M. V. Sarode, Head, Department of Computer Engineering and Dr. S. K. Kalaspurkar Principal, Jagadambha College of Engineering \& Technology, Yavatmal for constant inspiration and valuable advice. Words fall short to express my deep sense of gratitude towards them all, who have directly or indirectly helped me.

\section{References:}

Ananda Kanagraj S., Arjun G., Shahina A., "Cheeka: A Mobile Application for Personal Safety", 9th IEEE International Conference on Collaborative Computing: Networking Application and Work-sharing, Volume 1, Issue 1, pp.289 - 294, 20-23 October 2013.

Chandra A, Jain S, Qadeer $\mathbf{M} \quad \mathbf{A}$,“ Implementation of location awareness and sharing system based on GPS and GPRS using J2ME, PHP and Mysql ", 3rd international conference on Computer research and development( ICCRD), Volume 1, Issue 1, pp. 216- 220, 11-13 March 2011.

Daisuke Igaue, Takumi Ichimura, "Kids Protection Android System to Notice the Hazard in Dynamic Environment by Hierarchical Modular Reinforcement", 28th Fuzzy System Symposium, Nagoya, 12-14 September 2012 
Ito, A., Ohta, T., Inoue, S., "Security system for children on school route", International Symposium on Autonomous Decentralized system (ISADS), Volume 11, Issue 3, pp. 1 - 6, 23-25 March 2009.

J.Saranya, J .Selvakumar, "Implementation of Children Tracking System on Android Mobile Terminals", 2013 International conference on Communication and Signal Processing (ICCSP), Volume 1, Issue 1, pp.961 - 965, 3-5 April 2013.

Jianlin Xu, Yifan Yu, Zhen Chen , Bin Cao, Wenyu Dong, Yu Guo, and Junwei Cao, "MobSafe: Cloud Computing Based Forensic Analysis for Massive Mobile Applications Using Data Mining," Tsinghua Science and Technology, Volume 18, Issue 4, August 2013.
Rydell, J., St-Lau rent L., Prevost D., "Crowd analysis with target tracking, K-means clustering and hidden Markov models", 15th International Conference on Information Fusion (FUSION), Volume 1, Issue 1, pp.1903 - 1910, 9-12 July 2012.

Snehal P. Umratkar, Ram Kumar, "SecureChild: Children Tracking Android Application", International Journal of Scientific Research and Management, Volume 1, Issue3.

W. Enck, D. Octeau, P. McDaniel, and S. Chaudhuri, "A study of android application security" in USENIX Security Symposium, San Francisco, USA, 2011. 